\title{
PREVALENCE AND IMPACT OF PERIPHERAL NEUROPATHY ON QUALITY OF LIFE IN PATIENTS WITH DIABETES MELLITUS: PILOT STUDY
}

\author{
B. Levterova ${ }^{1 *}$, V. Naydenov ${ }^{2}$, Pl. Todorov ${ }^{3}$, G. Levterov $^{4}$ \\ ${ }^{1}$ Department of Health Management and Healthcare Economics, Faculty of Public Health, Medical \\ University - Plovdiv, Plovdiv, Bulgaria \\ ${ }^{2}$ Department of Neurology, Faculty of Medicine, Medical University - Plovdiv, University Hospital \\ „Kaspela“, Plovdiv, Bulgaria \\ ${ }^{3}$ Department of Propaedeutics of Internal Diseases, Faculty of Medicine, Medical University - \\ Plovdiv, Plovdiv, Bulgaria \\ ${ }^{4}$ Clinic of Endocrinology and Metabolic Diseases, University Hospital „Kaspela“, Plovdiv, Bulgaria
}

\begin{abstract}
PURPOSE of this study was to evaluate the prevalence and impact of diabetic peripheral neuropathy (DPN) on the quality of life of patients with diabetes mellitus. METHODS: A pilot cross-sectional study of patients with type 1 and type 2 diabetes mellitus (T1DM and T2DM) was conducted. Patients were divided into three groups: group $1=$ diabetic neuropathy with pain; group $2=$ diabetic neuropathy without pain; group 3 = lack of diabetic neuropathy. The quality of life was assessed by SF-36v2. RESULTS: The prevalence of DPN is $43 \%$ among the two groups of patients and higher T2DM (50.8\%) compared T1DM (25.6\%). DPN with pain was $14 \%$ among all subjects with DPN, which was again more often in patients with T2DM (17.9\%) than in patients with T1DM $(5.8 \%)$. Patients in group 1 had statistically significant lower QoL compared to group 2 in all 8 dimensions on SF-36. CONCLUSIONS: Diabetic neuropathy without and with pain is a common complication for type 2 diabetes mellitus. This condition can be identified with cheap and easy-to-use screening tools. Despite its profound impact on QoL, painful diabetic neuropathy remains under-studied.
\end{abstract}

Key words: Diabetes Mellitus (DM), Diabetic Peripheral Neuropathy (DPN), Quality of life (QoL), Douleur Neuropathique en 4 Questions (DN4), Medical Outcomes Study Short Form Health Survey version 2 (SF-36v2)

\section{INTRODUCTION}

Diabetes mellitus (DM) is one of the most common chronic diseases in the world. According to the International Diabetes Federation (IDF), individuals affected by DM are 425 million people worldwide, and this is expected to increase dramatically to about 628 million in 2045 [1]. The prevalence of diabetes mellitus (DM) in Bulgaria increased significantly, from $1.6 \%$ in 1990 to $9.6 \%$ in 2015 of the adult population [2, 3]. Diabetes mellitus is rising rapidly in the Bulgarian population mainly due to the rise in overweight and obesity [4]. Increasing prevalence of both type 1 and type $2 \mathrm{DM}$ results with an increase

\footnotetext{
*Correspondence to: Boryana Levterova, $15 \mathrm{~A}$

"Vasil Aprilov" Blv, 4002 Plovdiv, Bulgaria, email: boryana_levterova@abv.bg
}

in diabetes related complications, which also severely affect patients' Quality of Life (QoL) [5].

Diabetic peripheral neuropathy (DPN) is defined as a progressive loss of distal sensation initially effecting the lower extremities [6]. DPN is the most common long term complication of diabetes and is the main initiating factor for foot ulceration and lowerextremity amputation [7]. Diabetic peripheral neuropathy has significant impact on the quality of life of the patients with diabetes and can result in early death $[8,9]$. The prevalence of diabetic neuropathy varies from $23 \%$ [8] to $76 \%$ [10]. Poor glycaemic control, aging, long diabetes duration, visceral obesity, hypertension, smoking, hyperinsulinemia and 
dyslipidaemia are the most important factors implicated with disease progression [6-8].

Painful diabetic peripheral neuropathy (PDPN) is a common secondary complication of diabetes. Many patients with diabetic neuropathy experience neuropathic pain, typically characterized as burning, tingling, electric, sharp, shooting, and lancinating, which initially starts in both feet and may progress to involve calves, fingers, and hands (stocking and glove pattern) [11]. Pain associated with DPN substantially affects the QoL among patients with this condition [12].

There are several methods for early detection of DPN, ranging from quantitative methods: the rate of neural conduct (electromyography), the chamber vibration test, the nerve monofilament sensory test and the temperature test, to many validated questionnaires [13]. Different screening questionnaires have been developed since 2001 to identify neuropathic pain [14]. Douleur Neuropathique 4 (DN4) is one of these tools, originally developed and validated in France and reported in a number of international studies [15-17].

Purpose of this study was to assess the prevalence and impact of diabetic peripheral neuropathy (with and without pain) on the Quality of Life of patients with Diabetes Mellitus.

\section{MATERIAL AND METHODS}

This cross-sectional study was conducted at the Neurology department of University hospital "Kaspela", Plovdiv. Plovdiv is the second largest urban area in Bulgaria with an estimated population of 669,796 people. A descriptive pilot study was conducted among 37 patients with diabetes mellitus from January to March 2018. Eligible patients enrolled in the study fulfilled the following criteria: 1) over 18 years of age; 2) duration of DM of at least 1year according to the available medical records. All patients who were willing to participate completed an informed consent form, and all responses were anonymous.

Demographic and clinical data were collected by subject's medical records. Diabetic neuropathy was diagnosed after performing electromyography [14].

Health status was measured using the SF-36 version 2 (License No QM045452), administered as part of a self-completed questionnaire. The SF-36 is a generic questionnaire designed to examine a person's perceived health status [18]. It measures the following eight health dimensions: 1 .
LEVTEROVA B., et al.

limitations in physical activities because of health problems -Physical Functioning (PF); 2. limitations in social activities because of physical or emotional problems -Social Functioning (SF); 3. limitations in usual role activities because of physical health problems (Role/Physical) (RF); 4. Bodily Pain (BP); 5. general mental health (psychological distress and well-being) - Mental Health (MH); 5 6) limitations in usual role activities because of emotional problems; (Role/Emotional) (RE); 7. Vitality (energy and fatigue) - (VT); 8. general health perceptions $(\mathrm{GH})$ and the two derived summary scales, the physical component summary (PCS) and the mental component summary (MCS) [18-20]. The SF-36 scores range from 0 to 100 , with higher scores indicating better functioning, well-being, and state of health [21]. In the framework of an international project (IQOLA), SF-36v2 is translated and validated in Bulgarian for use in multinational clinical trials and other international studies [22].

Douleur neuropathique 4 questionnaire (DN4, painful neuropathy 4 questionnaire) was originally developed and validated in French. It is a clinician-administered questionnaire consisting of 10 items. Seven items related to pain quality (i.e. sensory and pain descriptors) are based on an interview with the patient and 3 items based on the clinical examination. The score ranges from 0 to 10 , with scores $\geq 4$ suggesting PDN [15].

To facilitate statistical analysis, patients with diabetes mellitus were divided into three groups: group $1=$ painful diabetic peripheral neuropathy (PDPN); group $2=$ diabetic peripheral neuropathy without pain; group $3=$ lack of diabetic peripheral neuropathy.

All statistical analyses were performed using SPSS version 17.0. We used methods of descriptive statistics, parametric and graphical analyses to process the obtained results. The sample data were expressed as frequencies and percentages for categorical variables or by mean values and standard deviation for continuous variables. P-value of less than 0.05 is regarded as statistically significant.

\section{RESULTS}

The study group included $21(56.8 \%)$ males and $16(43.2 \%)$ females with diabetes mellitus. The mean age was $58.3 \pm 2.7$ years in men and $56.2 \pm 3.9$ years in women (range: 27-85 years). Socio-demographic and other characteristics of the study sample are described in Table 1. 
Table 1. Characteristics of the study sample $(n=37)$

\begin{tabular}{|c|c|c|}
\hline Characteristics & $\mathbf{n}$ & $\%$ \\
\hline \multicolumn{3}{|l|}{ Gender } \\
\hline Male & 21 & 56.8 \\
\hline Female & 16 & 43.2 \\
\hline \multicolumn{3}{|l|}{ Education } \\
\hline Primary education & 12 & 32.4 \\
\hline Secondary education & 17 & 45.9 \\
\hline College and High & 5 & 13.5 \\
\hline Non response & 3 & 8.2 \\
\hline \multicolumn{3}{|l|}{ Marital status } \\
\hline Married & 27 & 73.0 \\
\hline Single /Widowed/ Divorced & 10 & 27.0 \\
\hline \multicolumn{3}{|l|}{ Employment status } \\
\hline Employed & 18 & 48.6 \\
\hline Retired & 16 & 43.2 \\
\hline Unemployed & 3 & 8.1 \\
\hline \multicolumn{3}{|l|}{ Diabetes Mellitus } \\
\hline Type 1 & 5 & 13.5 \\
\hline Type 2 & 32 & 86.5 \\
\hline Duration of DM $\geq 5$ years & 23 & 62.2 \\
\hline \multicolumn{3}{|l|}{ Complication } \\
\hline Neuropathy & 16 & 43.2 \\
\hline Retinopathy & 6 & 16.2 \\
\hline Nephropathy & 6 & 16.2 \\
\hline Ischemic Heart disease & 18 & 48.6 \\
\hline Hypertension & 28 & 75.7 \\
\hline Smoking (yes) & 6 & 16.2 \\
\hline \multicolumn{3}{|l|}{ DM treatment } \\
\hline Diet & - & - \\
\hline Oral only & 26 & 70.3 \\
\hline Oral + insulin injections & 5 & 13.5 \\
\hline \multirow[t]{2}{*}{ Insulin only } & 6 & 16.2 \\
\hline & Mean (SD) & Range \\
\hline Age & $57.4(5.85)$ & $27-85$ \\
\hline BMI $*(\mathrm{~kg} / \mathrm{m} 2)$ & $30.9(5.3)$ & $21.6-43.6$ \\
\hline HbA1c** & $7.89(0.9)$ & $6.1-9.9$ \\
\hline
\end{tabular}

*BMI= Body Mass Index; ${ }^{* * H b A 1 c}=$ Haemoglobin A1c;

Mean BMI in the subjects was $30.9 \pm 5.3$, ranging from 21.6 to 43.6 , or $52.9 \%$ of the patients were overweight or obese. The disease duration was $7.1 \pm 4.5$ years in men and $5.9 \pm$ 3.2 years in women (range: 1.3-22.5 years). Patients treated with at least one oral medication were $70.3 \%$ and patients on insulin therapy only was $16.2 \%$. The mean HbA1c was $7.9 \pm 0.9 \%$.

The prevalence of DPN in the study population was $43.2 \%$ and was higher in patients with T2DM (50.8\%) compared with patients with T1DM (25.6\%). The incidence of PDPN was $13.2 \%$ of all patients with DM, again more common in T2DM (17.9\%) than in T1DM $(5.8 \%)$.

The SF-36v2 questionnaire uses Likert's traditional 6-degree scale from "excellent" to "very bad" health. The respondent's assessment of "General Health" indicates that most of them consider their status as "good" (49.7\%), with those with DN reporting worse overall health (Figure 1).

Male respondents perceived a better quality of life compared to women, especially in $\mathrm{PF}, \mathrm{MH}$, and GH. Overall, the SF-36 score was lower (51.5) in females than in males (62.1) and this difference was statistically significant $(\mathrm{P}<$ 0.05). Demographic factors such as: low levels of education, unemployed, unmarried people report poor QoL. Married patients reported better health in all areas and the differences are substantial BP, VT and MH (P <0.05). Single (Widowed/Divorced) subjects reported poor mental health that may be associated with a lack of emotional support from a partner and loneliness. 


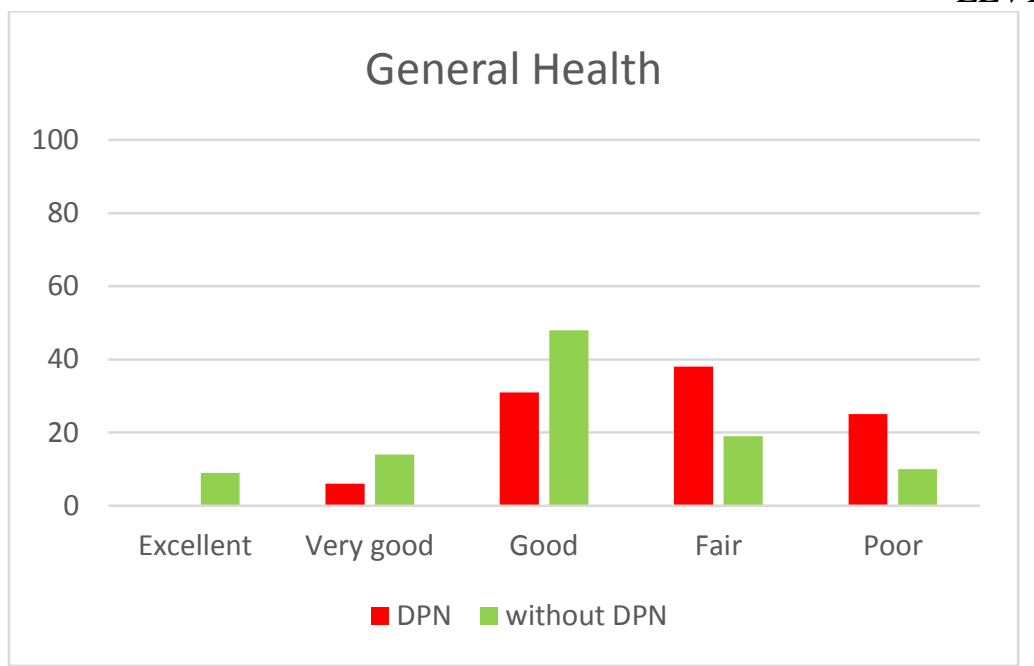

Figure 1. QoL in patients with DPN and without DPN

Patients in group 3 (lack of DPN) report a better QoL in all domains than in group 1 and group2. Statistically significant are these differences in PF, VT, BP and GH. Patients with a painful diabetic peripheral neuropathy was lower QoL than those with DPN without pain in all 8 dimensions of the SF-36. These differences are statistically significant from the PF, VT, BP and GH (Table 2).

Table 2. SF-36 profile of the study sample $(n=37)$

\begin{tabular}{|c|c|c|c|c|c|c|c|c|}
\hline & $\begin{array}{l}\text { Physical } \\
\text { Functioning } \\
\text { (PF) }\end{array}$ & $\begin{array}{l}\text { Role } \\
\text { Physical } \\
\text { (RP) } \\
\end{array}$ & $\begin{array}{l}\text { Role } \\
\text { Emotional } \\
\text { (RE) }\end{array}$ & $\begin{array}{l}\text { Vitality } \\
\text { (VT) }\end{array}$ & $\begin{array}{l}\text { Mental } \\
\text { Health } \\
\text { (MH) }\end{array}$ & $\begin{array}{l}\text { Social } \\
\text { Functioning } \\
\text { (SF) }\end{array}$ & $\begin{array}{l}\text { Bodily } \\
\text { Pain } \\
\text { (BP) }\end{array}$ & $\begin{array}{l}\text { General } \\
\text { Health } \\
\text { (GH) }\end{array}$ \\
\hline \multicolumn{9}{|l|}{ GENDER } \\
\hline Male & $55.75(4.43)$ & $49.39(4.09)$ & $53.65(3.71)$ & $48.78(2.91)$ & $54.63(2.92)$ & $52.58(3.53)$ & $50.51(4.35)$ & $59.21(2.22)$ \\
\hline Female & $50.72(5.91)$ & $40.30(4.64)$ & $42.52(4.60)$ & $41.37(3.09)$ & $50.17(3.19)$ & $51.21(3.80)$ & $39.17(3.64)$ & $40.62(3.54)$ \\
\hline P-value & 0.003 & 0.465 & 0.176 & 0.104 & 0.023 & 0.158 & 0.174 & 0.002 \\
\hline \multicolumn{9}{|l|}{ AGE } \\
\hline$<40$ years & $61.66(16.61)$ & $70.83(8.17)$ & $61.11(10.01)$ & $54.17(9.36)$ & $67.50(8.14)$ & $54.17(10.03)$ & $62.67(7.67)$ & $52.67(9.53)$ \\
\hline $\begin{array}{l}40-50 \\
\text { years }\end{array}$ & $58.07(11.56)$ & $68.75(12.04)$ & $57.29(11.83)$ & $48.43(7.81)$ & $60.00(7.13)$ & $54.68(11.77)$ & $32.37(8.95)$ & $47.50(4.59)$ \\
\hline $\begin{array}{l}51-60 \\
\text { years }\end{array}$ & $52.14(8.78)$ & $44.64(3.26)$ & $52.38(2.95)$ & $41.96(1.78)$ & $50.74(3.27)$ & $52.67(3.96)$ & $47.78(6.49)$ & $34.42(5.16)$ \\
\hline$>60$ years & $50.76(4.99)$ & $37.95(3.72)$ & $44.64(3.70)$ & $45.24(2.98)$ & $50.00(2.83)$ & $50.59(3.40)$ & $42.07(3.40)$ & $42.07(3.57)$ \\
\hline P-value & 0.001 & 0.851 & 0.234 & 0.557 & 0.048 & 0.953 & 0.264 & 0.046 \\
\hline \multicolumn{9}{|c|}{ DURATION OF DIABETES } \\
\hline$<5$ years & $55.05(4.44)$ & $53.17(3.98)$ & $50.62(4.19)$ & $46.53(3.57)$ & $53.15(3.30)$ & $53.70(4.47)$ & $45.07(4.13)$ & $41.88(2.62)$ \\
\hline$>$ 5years & $47.23(7.30)$ & $40.69(4.25)$ & $48.06(3.79)$ & $45.20(2.75)$ & $52.59(2.88)$ & $50.58(3.30)$ & $40.37(3.89)$ & $40.37(3.89)$ \\
\hline P-value & 0.044 & 0.472 & 0.662 & 0.768 & 0.896 & 0.570 & 0.827 & 0.179 \\
\hline \multicolumn{9}{|l|}{ DPN } \\
\hline No & $67.92(7.59)$ & $57.29(8.20)$ & $61.11(7.96)$ & $50.52(6.36)$ & $58.33(6.44)$ & $60.41(3.72)$ & $53.75(7.61)$ & $47.25(5.26)$ \\
\hline $\begin{array}{l}\text { Yes } \\
\text { (without } \\
\text { pain) }\end{array}$ & $49.68(4.35)$ & $43.21(3.28)$ & $46.55(2.90)$ & $34.71(2.26)$ & $51.63(2.25)$ & $50.00(3.06)$ & $41.83(3.03)$ & $38.25(2.05)$ \\
\hline $\begin{array}{l}\text { Yes (with } \\
\text { pain) }\end{array}$ & $47.05(4.99)$ & $41.03(5.23)$ & $45.97(4.15)$ & $31.15(3.70)$ & $49.87(8.65)$ & $49.56(7.09)$ & $40.09(1.98)$ & $36.56(3.56)$ \\
\hline P-value & 0.016 & 0.496 & 0.322 & 0.012 & 0.095 & 0.091 & 0.031 & 0.025 \\
\hline
\end{tabular}

Statistically significant are the relationships between the presence of DPN (with and without pain) and the quality of disease control and DM duration $(\mathrm{P}<0.05)$. Those with longterm diabetes mellitus duration and poor glycaemic control have a lower QoL. Duration of DM seems to be the most influential factor which negatively and statistically significant affects all the SF-36 subscales, particularly in the case of the group of "5 and more years".

The mean DN4 score in patients with diabetic peripheral neuropathy was $3.8+$ SD 1.4. Of these, DN4 $\geq 4$ have $13.5 \%$, and these are patients with PDPN.

\section{DISCUSSION}

Although diabetes is known to be a serious burden for the Bulgarian system of public health, there are still quite scarce studies that assess the impact of diabetes and its complication on the patients' quality of life [23].

We investigated the association of demographic, social and diabetes-specific variables on the QoL of DPN patients in Plovdiv. A cohort study of 37 subjects with diabetes mellitus was conducted to measure the QoL in the presence of diabetic peripheral neuropathy (with pain and without). DPN is a 
more common complication in patients with T2DM as evidenced by other studies [6-9]. Kamenov et al. reported a prevalence of $75.7 \%$, while our study rate was $43.2 \%$ [10]. The widespread variation in the incidence of the disease in same studies can be explained by the use of different diagnostic criteria for making the diagnosis of PDN and inclusion criteria on the specific study [8-10].

The results demonstrated that patients with DPN had significantly lower QoL compared to a previous research concerning the people with diabetes mellitus in Bulgaria [5, 23]. Women with diabetes mellitus reported a lower quality of life than men, with statistically significant differences in physical functioning, mental health and general health. This is in line with the reported gender differences in the total population and persons with DM [5, 23-26]. Studies have shown that men were more confident of their ability to control diabetes and reported a higher quality of life and were less likely to get depression or anxiety compared to women. Women often experience role-play conflicts in the day-to-day management of diabetes, which is related to the reconciliation of many roles - household, workplace responsibilities and realization in the profession [26].

Quality of life in patients with DPN could be affected by various factors. Numerous demographic factors such as age, marital status, education and employment status, have been found to influence QoL. Bivariate analysis showed significant correlations with age, education, marital and employment status. Single (Widowed/Divorced) reported poor mental health that may be associated with a lack of emotional support from a partner and loneliness. A lower level of education, lack of employment, uncontrolled diabetes mellitus and insulin use have a negative impact on QoL. Duration of DM seems to be the most influential factor which negatively and statistically significant affects all the SF-36 subscales. Similar results have been reported by a number of other studies, which may be due to lower health culture or poor compliance with therapy in these groups [5, 23, 26-27].

Our results thus confirmed what has been documented about the severity of the pain experience among DPN patients in other studies $[28,29]$. Chronic pain often restricts a patient's ability to perform important daily activities, thereby compounding the negative impact of pain. Patients who do not have diabetic neuropathy report a higher QoL than patients with DPN [28].
LEVTEROVA B., et al. Painful diabetic peripheral neuropathy is one of the forms of DPN that affects between 16 and $34 \%$ of patients with DM. In our study, the incidence of PDPN was $13.5 \%$ and was lower than that reported in other studies, which may be due to the small sample of the study $[9,11]$. Patients with PDPN have a worse QoL compared to those with DPN without pain and those without DPN in all 8 dimensions on SF36. The pain has greatest impact on PF, VT, $\mathrm{SF}, \mathrm{BP}$ and $\mathrm{GH}$. This leads to a limitation of movement, physical endurance and difficulty in carrying out day-to-day activities. Previous studies have reported that patients with diabetes with neuropathic pain develop more often depression, anxiety and sleep disturbances than painless neuropathy. The intensity of pain is associated with more cases with severe depression and poor QoL [27-29].

Patients with pain and treated with insulin reported worse QoL than those treated with diet and / or oral agents. These results are confirmed in other studies [30]. Switching to daily insulin application, as well as the need for more rigorous control, cause additional stress for patients and lower even more the quality of life [5, 23].

\section{CONCLUSIONS}

Diabetic peripheral neuropathy (with or without pain) is a very common complication of diabetes mellitus, especially in patients with a s type $2 \mathrm{DM}$.

The results of the present study suggest that good QoL is significantly related to good diabetes self-management and HbA1c control in patients with DPN. Therefore, in order to preserve a good HRQOL, it is obviously important to prevent diabetes complications and properly manage concomitant chronic diseases even when the patient has already DPN.

Diabetic pain neuropathy can be identified with inexpensive and easy-to-use screening tools such as the DN4 questionnaire. Additional studies, including a larger sample size, are needed to measure the impact of DN (with or without pain) on the QoL of patients with DM.

\section{REFERENCES}

1. International Diabetes Federation. IDF Diabetes Atlas, 8th edn. Brussels, Belgium: International Diabetes Federation, 2017. Available from:

http://www.diabetesatlas.org

2. Charakchiev, D., et al., Establishing a national register of patients with diabetes mellitus. Social Medicine; 1: 19-21, 2015. 
3. Borissova, A-M., et al., Changes in the Prevalence of Diabetes Mellitus in Bulgaria (2006-2012). Clinical medicine insights: Endocrinology and diabetes ,8: 41-45, 2015.

4. Borisova, A-M., et al., Frequency and role of the risk factors for the occurrence of diabetes and pre-diabetes in the Bulgarian population. Endocrinologia,;18: 188-195, 2013.

5. Levterova, B., et al., Quality of Life in Patients with Type 2 Diabetes Mellitus in Bulgaria: A Cross-Sectional Study. European Journal of Preventive Medicine, 4: 7-12, 2016.

6. Tesfaye, S., Neuropathy in diabetes. Medicine, 38: 649-655, 2010.

7. Young, M. J., et al., A multicentre study of the prevalence of diabetic peripheral neuropathy in the United Kingdom hospital clinic population. Diabetologia, 36: 150154, 1993.

8. Tesfaye, S., et al., Prevalence of diabetic peripheral neuropathy and its relation to glycaemic control and potential risk factors: the EURODIAB IDDM Complications Study. Diabetologia, 39: 1377-1384, 1996.

9. Davies, M., et al., The prevalence, severity, and impact of painful diabetic peripheral neuropathy in type 2 diabetes. Diabetes care, 29: 1518-1522, 2006.

10.Kamenov, Z., et al., Incidence of diabetic neuropathy. J clin Med, 2: 39-48, 2009.

11.Veves, A., et al., Painful diabetic neuropathy: epidemiology, natural history, early diagnosis, and treatment options. Pain medicine, 9: 660-674, 2008.

12.Tsuji, M., et al., Painful diabetic neuropathy in Japanese diabetic patients is common but underrecognized. Pain Study and Treatment, 2013.

13.Smith, S. C. , et al., Measuring healthrelated QOL in diabetic peripheral neuropath: a systematic review. Diabetes Study and Clinical Practice, 96: 261-70, 2012.

14.Bennett, M. I., et al., Using screening tools to identify neuropathic pain. Pain, 127: 199-203, 2007.

15.Bouhassira, D., et al., Comparison of pain syndromes associated with nervous or somatic lesions and development of a new neuropathic pain diagnostic questionnaire (DN4). Pain, 114: 29-36, 2005.

16.Perez, C., et al., Validity and reliability of the Spanish version of the DN4 (Douleur Neuropathique 4 questions) questionnaire for differential diagnosis of pain syndromes associated to a neuropathic or somatic
LEVTEROVA B., et al. component. Health and quality of life outcomes, 5: 66, 2007.

17.Spallone, V., et al., Validation of DN4 as a screening tool for neuropathic pain in painful diabetic polyneuropathy. Diabetic Medicine, 29: 578-585, 2012.

18. Ware Jr, J.E., Sherbourne, C. D., The MOS 36-item Short-Form health survey (SF-36). I. Conceptual framework and item selection. Med Care, 30:473- 483, 1992.

19.McHorney, C. A., et al., . The MOS 36Item Short-Form Health Survey (SF-36) II: psychometric and clinical tests of validity in measuring physical and mental health constructs. Med Care, 31: 247-263, 1993.

20.Ware Jr, J.E., et al., SF-36 physical and mental health summary scales: a user's manual. The Health Institute, 1994.

21.Ware Jr, J.E., et al., How to score version two of the SF-36 Health Survey, Lincoln (RI): QualityMetric, 2000.

22.Ware, J.E., Gandek, B., Overview of the SF-36 Health Survey and the International Quality of Life Assessment (IQOLA) project. J Clin Epidemiol, 51:903-1012, 1998.

23.Levterova, B.A., et al., Bulgarian version of the Audit of Diabetes-Dependent Quality of Life (ADDQoL-19). Biotechnology \& Biotechnological Equipment, 31: 581-587, 2017.

24.Iskrov, G., Hristova, E., Stefanov, R., Population Quality of Life Standards in Bulgaria - Preliminary Results of a National Representative Study with EQ-5D. .Rare Diseases and Orphan Drugs, 6 (Suppl 1), 2015.

25.Watkins, K., Connell, C. M., Measurement of health-related QOL in diabetes mellitus. Pharmacoeconomics, 22: 1109-1126, 2004.

26.Rubin, R. R., Peyrot, M., Quality of life and diabetes. Diabetes/metabolism research and reviews, 15: 205-218, 1999.

27.Cheah ,W.L., et al., Perception of QOL among people with diabetes. Malaysian Family Physician, 7: 21-30, 2012.

28. Olmez, N., Degirmenci, Y., Kececi, H. Effects of pain and disability on QOL. Neuroscience \& Medicine, 6: 98-106, 2015.

29.Chiles, N.S., et al., Diabetes, peripheral neuropathy, and lower extremity function. Journal of Diabetes and Its Complications, 28: 91-95, 2014.

30.Singh, R., Kishore, L., Kaur, N., Review Diabetic peripheral neuropathy: current perspective and future directions. Pharmacol Res, 80:21-35, 2014. 